\title{
O carro de Jagrená por entre palácios de cristal. Um ensaio sobre a transparência na gestão democrática das cooperativas
}

The Jagrena's chariot among crystal palaces. An essay on transparency in the cooperatives democratic members control

Guilherme Gomes Krueger ${ }^{1}$

Universidade Estadual do Rio de Janeiro (Brasil)

Sumário: 1. Introdução. 2. Um manual para o chofer do carro de Jagrená. 3. A polifonia e a realidade entre a tragédia e a utopia. 4. O Castelo de cristal e o homem-rato no seu subsolo. 5. Agora sim, posso falar nas cooperativas. 6. Conclusão: do homo politicus no homo felix. Referências bibliográficas.

Summary: 1. Introduction. 2. A Jagrena's chariot driver handbook. 3. Polyphony and reality between tragedy and utopia. 4. Crystal palace and its underground mouse man. 5. Right now, I can talk about cooperatives. 6. Conclusion: From homo politicus to homo felix. 7. References.

Resumo: Um exercício hermenêutico da gestão democrática de uma cooperativa. Uma esquizoanálise desse princípio de sua identidade. Esta análise específica é realizada com a correlação entre a segurança ontológica, por Anthony Giddens e o ressentimento, como narrado por Fiódor Dostoiévski. A correlação se referencia no realismo com que ambos, Giddens e Dostoiévski, qualificam as respectivas obras e explora a diferença que há entre as abordagens. O realismo de Giddens pressupõe uma dialética, inexistente no de Dostoiévski. A obra de Dostoiévski então sugere nuances sobre o significado ético atribuído à transparência que costuma se apresentar como um critério para a performance da gestão democrática das cooperativas. Um sentido escatológico aparece na transparência, quando se considera o mal inafastável da história humana, eis que o ressentimento é uma manifestação material de sua existência.

Palavras-chave: Hermenêutica - gestão - transparência - segurança - ressentimento.

1 Email: guilherme@gomeskrueger.adv.br 
Abstract: A hermeneutic exercise of the democratic management of a cooperative. A psychoanalysis of this principle of its identity. This specific analysis is carried out with the correlation between ontological security, by Anthony Giddens and resentment, as narrated by Fyodor Dostoevsky. The correlation is referenced in the realism with which both Giddens and Dostoevsky qualify the respective works and explores the difference that exists between the approaches. The realism of Giddens presupposes a dialectic, non-existent in that of Dostoevsky. Dostoevsky's work then suggests nuances about the ethical significance attributed to the transparency that tends to present itself as a criterion for the performance of the democratic management of cooperatives. An eschatological sense appears in transparency, when one considers the unshakable evil of human history, behold, resentment is a material manifestation of its existence.

Keywords: Hermeneutics - management - transparency - security - resentment. 


\section{Introdução}

É normal que a transparência se apresente como um critério de avaliação da gestão democrática das cooperativas. Este ensaio é um exercício hermenêutico da transparência aí. Este exercício é realizado com uma esquizoanálise.

A esquizoanálise não esgota numa diacronia a percepção da transparência para a gestão democrática da cooperativa ${ }^{2}$. Ao invés, alude a estruturas inconscientes que são vislumbradas em um discurso com referências estéticas. A estética aí permite desprender um bem (a democracia) de sua relação com fins dados. Em última instância, a felicidade. O bem é resgatado para sua relação com o mal; relação esta insondável à razão, quando reduzida a uma lógica, a um consenso ou a um acontecimento transcendental, enfim a qualquer linearidade passado/ futuro para a relação interioridade/exterioridade entre ser humano e mundo, eis que o corpo humano é assumido como campo fenomênico imediato. Em outras palavras, trata-se de um ensaio de discurso que escapa de qualquer determinação teleológica para a gestão democrática. Isso porque a estética explora percepções sensoriais nas significações possíveis com o uso de linguagens. Então, a esquizoanálise é um exercício hermenêutico que não se prende à subjetividade, quando deriva o discurso ético para uma patologia. Ela não se confunde com a psicologia: ao se soltar da subjetividade, se retrai a objetividade da gestão transparente e democrática de uma cooperativa.

A relevância deste exercício ensaístico está no encontro de expressões marginais à tradição analítica e pragmática ${ }^{3}$ para dizer da gestão democrática como uma determinação identitária das cooperativas. Essas expressões marginais se prestam a uma cartografia que não orienta ninguém entre meios e fins, enquanto analisa fenômenos. Ao invés, a cartografia é percebida como uma realização distintiva entre o estilo e o sintoma na gestão democrática de uma cooperativa.. Essa distinção

2 O ensaio, no entanto, faz remissões históricas com frequência. Estas remissões convidam leitores pouco acostumados com um discurso referenciado em estruturas inconscientes. Ajudam como referências, mas não se prestam propriamente como elementos de análise.

3 «Para filósofo como Hutcheson e Hume, a estética torna-se uma questão de sentimento; de gostar mais disto do que daquilo. O gosto é um segmento isolado e inexplicável da psicologia humana, e se trata simplesmente de um fato curioso, mas filosoficamente desinteressante (....). A filosofia analítica contemporânea herdou as debilidades de suas origens empirista (....), estabelecer as conexões precisas entre juízo e apreciação em estética é difícil - mais difícil ainda que em ética. Roger Scruton, Arte e Imaginação (São Paulo: É Realizações, 1017), 9-11. 
coloca em xeque a formalização da ética como uma lógica da moral; um pressuposto do discurso principiológico da Aliança Cooperativa Internacional. Esta formalização é o sintoma. O estilo é o realismo.

A Aliança Cooperativa Internacional, em Nov/2017 publicou um material institucional denominado $A$ matter of principle: Co-operatives in development ${ }^{4}$. O material se reveste de objetividade num evidente esforço de comunicação global. E ao fazê-lo, bosqueja narrativas realistas, eis que apresentadas como algo que vai sendo informado de passagem $^{5}$. $O$ texto insinua as narrativas pela mimese entre inscrição e visão dos fatos dados. No texto, o que se visualiza é o real. O que

4 «A matter of principle: Cooperatives in development», International Cooperative Alliance, acesso em 23 de maio de 2018, https://www.ica.coop/en/media/library/a-matter-of-principle-co-operatives-in-development.

5 «The Federación Uruguaya de Cooperativas de Vivienda por Ayuda Mutua (FUCVAM), allows low income locals to have access to dignified and durable housing, a model that has already expanded to 15 countries in Latin America, and includes other amenities such as community farms or day care»

(International Cooperative Alliance,2017) . "The Co-operative Alliance of Kenya (CAK) ensures that there are elections every year, presenting an enabling environment for effective participation where each member has a right to speak in meetings and stand for any elective position in the co-operative» (International Cooperative Alliance,2017).

«In Kerala, the Uralungal Labour Contract Co-operative Society started way back in 1925 for the benefit of 14 marginalised labourers who lost their livelihood due to their active participation in Indian Freedom Movement. Today, they are the leading co-operative society in the country uplifting standard of living of over 5.000 workers directly contributing to the development of the society» (International Cooperative Alliance,2017).

"Caminos (Roads) is a Uruguayan Co-operative formed by a group of mainly female health professionals in 2002 when the mutual for which they worked closed. Currently, Caminos provides quality employment to more than 100 people committed to selfmanagement.» (International Cooperative Alliance,2017).

"Moshi Co-operative University (MoCU) is the oldest training institution in Tanzania, and it's committed to the promotion of equal opportunities and constructive involvement in community development. Current university enrolment stands at more than 4.000 students in the fields of co-operative accounting, management, and rural development.» (International Cooperative Alliance,2017).

«In 2010, Palestinian farmers in Jordan Valley decided to make their co-operatives work together to overcome the region's restrictions on movement and access to resources, markets, and services. The Seedling Nursery in Jordan Valley now is run by three different co-operatives: The Northern Jordan Valley Agriculture Co-operative, Ein Al Beda Agriculture Co-operative and Al Khadra Agriculture Co-operative, whose 245 farmers benefit from the nursery's quality, prices, and seed compatibility.» (International Cooperative Alliance,2017).

«In Mexico, since 2008, "Caja Popular Mexicana», a savings and credit co-operative, has been running a big program of social responsibility for their 2 million members. Their scholarship program has benefited over 56.000 students.» (International Cooperative Alliance,2017). 
há entre o real e o realismo? Uma escolha que se mostra na visão que não visa o que poderia ser. Visa o que só pode, porque já é. O que já é, é consumado. Sobre o consumado, se exerce domínio. Aqui, o seu empoderamento sobre a insaciedade pelo que a democracia flerta perigosamente com a vontade de potência. Toda combinação realismo/ idealismo retrai no inscrito a vontade presente em qualquer descrição. Quero dizer, quais são os sentidos possíveis do que não foi descrito numa descrição realista? Esta é a realização do real no realismo, porque o realismo visa o realizado, e não a realização. No lugar da realização, impera o procedimento.

O que quero enfatizar aqui? A principiologia identitária das cooperativas já é o que disso se espera. Eis que seu fim já está dado desde antes do seu escrever. O imaginário desse fim programático encontra sua expressividade como desenvolvimento na publicação da $\mathrm{ACl}$ aqui comentada. Mas, se democracia é gestão da vontade de potência pela vontade de verdade, uma linguagem realista do real, como qualquer outra, sempre esconde tanto quanto mostra. E o que esconde, é escondido pelo que mostra: uma totalidade ilusória do real. Porque realismo não é somente realidade mostrada; é também uma linguagem. Portanto, uma realização. Uma, dentre possíveis realizações. Aqui me concilio com essa literatura: mantenho a sua visada na alternância de poder. Também aqui o traio por não a assumir como natureza da democracia. $E$, sim, como aquilo dela que é além do natural. É um platô; um lineamento; uma cartografia.

Assumindo como linguagem o que a literatura da $\mathrm{ACl}$ nos inscreve na perspectiva de uma quarta parede, a diferença num conjunto conceitual oculta a oscilação vivenciada para se mostrar como uma questão de certeza e previsibilidade. Certeza é muito desejada pela Aliança Cooperativa Internacional. Então, para um regime democrático, tanto melhor quando seu devir seja visado mais pelos interesses e menos pelos desejos.

O interesse sobrecarrega de faticidade o horizonte visado pela literatura em seu primeiro plano. O desejo, neste plano, se mostra numa governança como retração das paixões brutais, quando manifestas entre os governados. Carregando o desejo algum sentido de presença da falta, há num desejo sempre algo em jogo de atração e retração. Há algo de desejável em qualquer ideal que não seja só formal, ou seja, pura função. Na urbe, ressignificada assim resta a via direita em face ao sinistro. Num sentido de engenhosidade que aproxima política da arquitetura. 


\section{Um manual para o chofer do carro de Jagrená}

O impacto do pensamento de Anthony Giddens pode ser vislumbrado no filme A Rainha 6 . Nele, o Primeiro Ministro britânico Tony Blair é retratado com marcada preocupação com os riscos da situação posta pelo enredo. Não se trata da boa e velha prudência, porque é perceptível um relativismo estratégico em suas opiniões. Esse niilismo racional é um elemento de construção da tensão dramatúrgica face à atônita

Rainha Elizabeth, porque ela ainda se apega às virtudes pessoais como a essência de um monarca à altura de suas funções. No caso, a fortaleza. Porém, as virtudes pessoais se tornam secundárias para a gestão procedimental da crise, tal como propõe Tony Blair nos dias que se sucedem à morte da Princesa de Gales, diante da comoção popular amplificada pelos meios de comunicação.

O que se vê aí é o aparecimento da gestão de riscos que, a partir dos anos 90, vai se tornando um paradigma aplicável até mesmo numa governança tão estável e cristalizada como é a monarquia britânica.

A obra de Anthony Giddens é notável por seu esforço de sistematização das características gerais de uma época que cunhou como modernidade radicalizada. É uma referência importante (e nada ingênua) para o conceito de sociedade de risco. E ela está sintetizada na alusão, um tanto paradoxal, ou talvez pretensiosa, de ser possível uma condução humana para o carro de Jagrená7. Ele é o Senhor do Mundo. Seu carro corre sem que se saiba bem por qual caminho vai e por isso marca com a destinação (nem sempre querida ou esperada) os seres humanos que encontra ${ }^{8}$.

Para Giddens, esse carro de trajetória errática simboliza os descaminhos da razão, tal como concebida e cultivada na modernidade. Esses descaminhos ocorrem como consequências involuntárias da reflexividade e circularidade do conhecimento social ${ }^{9}$. Por circularidade, característica inerente à modernidade, a cognição afeta sempre a dinâmica do próprio aparecer de um fenômeno: "as ciências sociais estão na ver-

6 The Queen (Original); data de lançamento: 1.\%10/ 2006. Dirigido por Stephen Frears. Roteiro de Peter Morgan Sinopse: A notícia da morte da princesa Diana se espalha rapidamente pelo mundo. Incapaz de compreender a reação emocional do público britânico, a rainha Elizabeth II (Helen Mirren) se fecha com a família real no palácio Balmoral. Tony Blair (Michael Sheen), o recém-apontado primeiro-ministro britânico, percebe que os líderes do país precisam tomar medidas que os reaproximem da população e é com essa missão que ele procura rainha.

7 Anthony Giddens. As consequências da modernidade (São Paulo: Editora UNESP, 1991), 165.

8 Giddens, As consequências..., 145.

9 Giddens, As consequências..., 166. 
dade mais profundamente implicadas na modernidade do que as ciências naturais, na medida em que a revisão crônica das práticas sociais à luz do conhecimento sobre estas práticas é parte do próprio tecido das instituições modernas» ${ }^{10}$. A reflexividade é definida como conhecimento organizado e governado pela observação empírica e pela lógica analítica, sempre focada na tecnologia e nos resultados apurados pela aplicação da normatividade moral e jurídica. De tal modo que «a descoberta de si torna-se um projeto diretamente envolvido com a reflexividade na modernidade» ${ }^{11}$. Como se depreende, Giddens não se esquiva em enfrentar a confiança e a certeza como problemas numa abordagem com referências ontológicas.

Este é o seu ponto de inflexão. Eis que a proposta de sua obra é um contraponto pragmatista à literatura francófona que ganhou projeção acadêmica nos anos 80 e que ele próprio genericamente nominou pós-moderna (em particular, se refere aos postulados apresentados por Lyotard). Isso, porque, embora reconheça o fracasso do monumental projeto hegeliano de determinação fenomenológica ${ }^{12}$ da verdade, permanece com sua fé nas «características universais das reivindicações de verdade» ${ }^{13}$. O pragmatismo em sua profissão de fé se revela numa sutileza, pois ele afirma que a universalidade se apresenta no que se reivindica como verdade. O que não é o mesmo que afirmar a universalidade presente na verdade em si mesma (aí denotaria uma metafísica). Seu viés pragmatista também se mostra, quando aponta aí um sentido próprio de nexo causal: ela se impõe de maneira irresistível para o conhecimento sistemático que se valida, quando dá conta dos perigos que se mostram em escala global. Daí porque a obra de Giddens se torna uma referência para o conceito de sociedade de risco.

Giddens apresenta seu manifesto de condutibilidade do carro de Jagrená como uma expressão explicitamente dialética: realismo utópico. Nessa expressão, Giddens se alinha com a razão comunicativa de Habermas ${ }^{14}$, a

10 Giddens. As consequências..., 51.

11 Giddens. As consequências..., 135.

12 Esse projeto filosófico é concebido partir da releitura dos fragmentos de Heráclito. Uma releitura que só foi possível com o historicismo emergente na literatura alemã que lhe precedeu.

13 Giddens. As consequências.., 163.

14 No plano habermasiano da pragmática universal, a razão substantiva foi esvaziada pela modernidade, fracionando-se em meras metodologias formais. Lida-se com a diversidade de alegações de verdade/validade através da linguagem dialógica, na figura da razão comunicativa, útil para o pragmatismo, mas para a qual a vida concreta é inacessível. Esta concepção da razão desvincula-se da perspectiva «logocêntrica» da filosofia, e volta-se para o discurso pelo discurso. Sobre linguagem e razão em Haber- 
pragmática transcendental de Apel15 e a democracia cooperativa de Dewey ${ }^{16}$, na medida em que (quando voltada ao esforço em solucionar problemas comuns), a linguagem é o lugar universal das reivindicações de verdade (clarificação/validação das ideias, quando submetidas à análise lógica ex ante e ao crivo da observação ex post da faticidade delas, ou seja, dos resultados da aplicação prática do conceito). Este lugar, tal como Hegel, Giddens identifica como sendo a dialética. Daí porque ele vê a modernidade radicalizada como um conjunto de circunstâncias em que a dispersão (tão presente na literatura pós-moderna) está interagindo com tendências para uma integração da ordem jurídica e moral: a complexidade. Giddens, aliás, por risco, está teorizando uma relação dinâmica e histórica entre impotência e empoderamento, tanto na vivência (o que ele qualificará como algo ontológico, ou seja, a presença/ausência do ser no mundo) como na ação prática contemporânea.

Por realismo utópico, Giddens postula que as mudanças sociais desejadas estão necessariamente vinculadas às possibilidades institucionais imanentes ${ }^{17}$. Trata-se então de uma autorrealização institucional como fundamento de uma autoidentidade moral, que na modernidade se mostra como um entrelaçamento de distâncias e proximidades espaçotemporais, tanto na vivência pessoal e como na economia de escala. Em

mas, cf. Maeve Cooke, Language and Reason: A Study in Habermas's Pragmatics (Cambridge: MIT Press, 1994).

15 Karl-Otto Apel concebe a verdade como uma ideia regulativa universalmente pressuposta. Desta forma, a transcendentalidade da verdade é revelada através do diálogo, idealmente em meio a uma comunidade de pesquisadores, debatedores e especialistas dedicados. Cf. Albrecht Wellmer. «Der Streit um die Wahrheit. Pragmatismus ohne regulative Ideen» em Reflexion und Verantwortung, Auseinandersetzungen mit Karl-Otto Apel, Ed. por D. Böhler; M. Kettner; G. Skirbekk (Frankfurt: Suhrkamp: 2004), 143-170.

16 «Democracia é a crença de que mesmo quando necessidades e fins ou conseqüências são diferentes para cada indivíduo, o hábito de cooperação amigável —que pode incluir, como no esporte, rivalidade e competição- é em si um acréscimo valioso à vida. [...] Uma fé genuinamente democrática na paz é uma fé na possibilidade de administrar disputas, controvérsias e conflitos como tarefas cooperativas em que ambas as partes aprendam dando à outra a chance de se expressar, ao invés de uma parte conquistar pela supressão da outra à força - uma supressão que é violenta quando ocorre através de meios psicológicos de ridicularização, abuso, intimidação, ao invés de aprisionamento aberto ou em campos de concentração. Cooperar dando uma chance às diferenças de se mostrarem por causa da crença que a expressão da diferença é não só direito de outras pessoas, mas um meio de enriquecer sua própria experiência de vida, é inerente ao modo de vida pessoal democrático.» John Dewey, Democracia cooperativa: Escritos políticos de John Dewey. Ed. por Augusto de Franco e Thamy Pogrebinschi (Porto Alegre: EDIPUCRS, 2008), 140.

17 Giddens, As consequências... ,169. 
outras palavras, a complexidade contemporânea cria sentidos dispersivos e fragmentários para o mundo, mas, por outro lado, possibilita diversos processos identitários para as pessoas. Se as pessoas não são um campo fenomênico de choque entre conceitos e leituras incessantemente criados, a vida cotidiana suporta a apropriação dos sistemas abstratos entrecruzados, ou seja, encontra formas de adaptação à complexidade performática que notabiliza a contemporaneidade. Essa adaptação passa por engajamentos pessoais, desde que coordenados nos diferentes espaços da polis, agora compreendida numa dimensão radicalmente contemporânea, isto é, a partir da tensão entre desencaixes e reencaixes espaçotemporais e do trânsito entre sistemas peritos que produzem essa dialética. Em suma, risco é (pragmaticamente) adaptação às situações criadas com as guinadas e rebusteios do carro de Jagrená.

Estou particularmente interessado naquilo que, referente aos riscos, ele nomina segurança ontológica: o risco como recusa à tragédia, ou, num sentido contraditório, o risco é uma tragédia de baixa intensidade, porque reflexiva e antecipada. Neste ponto, será interessante referenciar o risco na obra de Daniel Bell ${ }^{18}$. O que Giddens figura como o carro de Jagrená, Bell conceitua como história disjuntiva. É que Bell compreende a dinâmica da história por meio da escassez (dimensão econômica), violência (dimensão política) e diferença (dimensão cultural).

Mas, Giddens está explicitamente interessado em pôr-se num contraponto à literatura (pós-moderna) que recusa qualquer reconciliação funcional entre humanidade e natureza ${ }^{19}$, de forma que a ética nada mais pode ser do que uma genealogia/arqueologia da moral20. Neste

18 Cf. Daniel Bell. Las contradicciones culturales del capitalismo (Madrid: Alianza Editorial, 2004).

19 Natureza aqui tem um sentido próprio: diz-se natural aquilo que for sujeito a alguma determinação extrínseca.

20 Nietzsche identificou a consciência moral com uma tendência humana de examinar em si mesmo a transgressão, o que por sua vez se teria desenvolvido com a necessidade socioevolutiva de se inibir o extravasamento de instintos animalescos e cruéis contra terceiros, de forma que passamos a voltar estas pulsões a nós mesmos. Desta forma, o autor nega fundações transcendentais para a ética, vinculando-a a conceitos morais atávicos, investigáveis através da genealogia e da arqueologia. Friedrich Wilhelm Nietzsche, A Genealogia da Moral. 3. ${ }^{a}$ ed. Tradução de Antônio Carlos Braga. ( São Paulo: Escala, 2009). Foucault aprofundou este método crítico enquanto «uma espécie de procedimento que, despreocupado com a legitimação e consequentemente excludente quanto ao ponto de vista fundamental da lei, corre pelo ciclo de positividade por partir do fato da aceitação do sistema de aceitabilidade analisado pelo jogo do saber-poder. Digamos que este é, aproximadamente, o nível arqueológico [de análise]» Michel Foucault, "What is Critique?» em The Politics of Truth, Ed. por Sylvère Lotringer (Nova lorque: Semiotext[e], 2007), 61. 
ponto, há uma dialética entre a pós-modernidade e a modernidade radicalizada, visto que, em resposta aos franceses do pós-guerra que se tornaram leitores atentos de Saussure, Husserl e Nietzsche, o pragmatismo em Giddens apresenta uma ética formalizada, isto é, como lógica que se vislumbra da moral, quando dá conta dos riscos, isto é, quando evita desfechos trágicos em alta intensidade pessoal e impacto social. O mundo vai mudando inesperadamente na história, mas permanece no tecido social um sentimento (intencionalidade emocional) de integridade (inclinação para a coesão social):

A confiança, a segurança ontológica, é um sentimento da continuidade das coisas e pessoas permanecem intimamente ligadas entre si na personalidade adulta. A confiança na fidedignidade de objetos não humanos (....) é baseada sobre uma fé mais primitiva na fidedignidade e sustentação de seres humanos. A confiança nos outros é uma necessidade psicológica de um tipo persistente e recorrente. Tirar a segurança da fidedignidade ou integridade de outros é uma espécie de ranhura emocional que acompanha a experiência de ambientes familiares, sociais e materiais. A segurança ontológica e a rotina estão intimamente vinculadas, através da influência difusa do hábito. (....) A previsibilidade das rotinas (aparentemente) sem importância da vida cotidiana está profundamente envolvida com um sentimento de segurança psicológica. (....) A continuidade das rotinas da vida diária só é conseguida através da vigilância constante das partes envolvidas - embora isto seja quase sempre realizado por uma consciência prática. (....) [A] suspensão da confiança no outro enquanto agente fidedigno e competente é um transbordamento de ansiedade existencial que assume a forma de sentimentos de mágoa, perplexidade e traição, junto com suspeita e hostilidade.

Giddens enfatiza que a confiança ontológica demanda uma metodologia sofisticada para a consciência prática, que vem a ser um dispositivo (moral que transitou para o Direito pelo conceito de responsabilidade objetiva) de proteção contínua, ainda que admita um percurso histórico recorrentemente disjuntivo, como dissertado por Daniel Bell. A proteção então não se dirige ao acontecimento das disjunções históricas, estas inevitáveis. Mas, contra as ansiedades existenciais que (mesmo dos encontros e desencontros mais casuais com a alteridade) emergem como se a condição humana fosse um abismo pessoal..

Chego aqui a um ponto crucial da percepção do que seja gestão de risco e de como Giddens deposita sua fé na razão prática e na lógica das linguagens. Mas, ele demonstra a plausibilidade envolvente de seu discurso em contraponto à literatura pós-moderna. Lanço-me então ao desafio em estabelecer um contraponto ao realismo utópico 
proposto por Giddens, uma vez que ele parece estar presente no imaginário social instituinte da gestão de risco e a a responsabilidade objetiva no Direito como um acontecimento ético em discurso. Mas, será mesmo que a ética pode ser efetivamente delineada pela cognição de uma lógica da moralidade?

Recorro ao realismo trágico de Dostoiévski.

\section{A polifonia e a realidade entre a tragédia e a utopia}

Interesso-me pelo caráter trágico dos personagens e polifônico dos diálogos de Dostoiévski, sendo a correlação entre tais características um contraponto ao realismo utópico de Giddens.

Dostoiévski escreveu em meados do século XIX e, portanto, há um lapso literário incontornável entre ele e Giddens. Este lapso é precioso, na medida em que Dostoiévski não se propôs a uma crítica. A negatividade em sua obra se mostra como literatura profética ${ }^{21}$. Ele proferiu um sonoro Não! às esperanças de Goethe na reconciliação entre humanidade e natureza22. E remeteu negativamente aos esforços reflexivos de totalização do real desde a raiz socrática de nossa civilização contemporânea.

A obra de Dostoiévski após seu encarceramento na Sibéria é carregada de uma certeza de que os descaminhos da racionalidade se repetirão e deslizam para uma escatologia. Ou seja, esses descaminhos não se apresentam "só» depois, mas estão presentes desde sempre numa relação que se possa chamar de percurso histórico. Há uma radical e irredutível diferença entre profecia e risco. Apurar um risco é um ato de vontade dirigida à destinação, conquanto a profecia seja um atravessamento angustiante pela impotência humana face à sua própria destinação.

Em que medida o tom profético de Dostoiévski pode apresentar nuances acerca da sociedade de risco em face ao pragmatismo de

21 Luiz Felipe Pondé, Crítica e Profecia: a filosofia da religião em Dostoiévski (São Paulo: LeYa, 2013), 31.

22 [Uma] ideia romântica de devoção à beleza, de adoração da natureza, e de poesia se tornou um aspecto importante da autopercepção alemã. No entanto, ao mesmo tempo parecia haver uma nódoa negra nessa ideia. Como era possível que, dentro de poucas gerações, os herdeiros dessa ideia estivessem enforcando, torturando e assassinando pessoas exatamente nas mesmas florestas em que Goethe sentava para escrever poemas? Essa imagem, por um lado radiante e por outro cheio de trevas, já foi chamada de «dicotomia Weimar-Buchenwald» Esses dois aspectos formam um microcosmo do dilema alemão, a face de Jano da Alemanha. Anders Rydell, Ladrões de livros. Tradução de Rogério Calindo (São Paulo : Planeta do Brasil, 2018) , 61. 
Giddens, quando a literatura pós moderna (com seu tributo a Nietzsche) já resgatou de alguma maneira o sentido trágico da existência humana? Tanto o pragmatismo anglófono, quanto o pós estruturalismo francófono carregam no imaginário uma mítica das Revoluções americana e francesa em percurso até as guerras de secessão americana e a franco-prussiana, 100 anos depois. Um mesmo imaginário acerca do racionalismo iluminista e do idealismo kantiano: um acontecimento inflexivo de superação da metafísica. Algo como uma maioridade filosófica do pensamento ocidental. Dostoiévski, no entanto, traz consigo um imaginário social distinto, eis que polarizado pela Ortodoxia cristã face ao Catolicismo romano. Em Dostoiévski, o acontecimento inflexivo não se dá com a modernidade, mas no aparecimento da escolástica em face à patrística. Tampouco se trata de uma superação, mas antes uma degeneração do pensamento em discursos. Portanto, há um acento de continuidade numa visão monista de mundo desde a metafísica tomista até a dialética hegeliana exposta na Fenomenologia do Espírito. A sua insistência é exatamente na esperança de reconciliação entre Homem e Mundo; reconciliação esperada, porque acessível à razão e ao alcance da vontade humanas. Enfim, que a libertação de um destino trágico tenha alguma coisa a ver com conceituação.

Não! é a obra de Dostoiévski. O que aparece nessa literatura em primeiro plano é o que se apresenta como algo muito difícil de ser conceituado e, por isso, se retrai facilmente para uma ética catafática ${ }^{23}$, implícita em discursos recorrentes que se pretendam pós-metafísicos: o mal. Na obra de Dostoiévski, a onipresença do mal se manifesta na universalidade radical (insuperável) da miséria humana ${ }^{24}$.

23 Tomo aqui a expressão catafático em sua designação ambígua: tanto um incidente da linguagem pela repetição de respostas (o que, de certo modo, está presente em toda redução conceitual do real como realidade decifrada), como uma recorrência do ser, para que sua totalidade possa ser inferida pelos atributos do conhecer. No limite do conhecer, o resto inalcançável pela cognição, um conceito totaliza o real: mistério.

24 Recurso que ele já havia lançado mão em Notas do Subsolo, o anonimato nos Sonhos de um Homem Ridículo de Fiodor Dostoiévski, Duas Narrativas Fantásticas.Tradução de Vadim Nikitin. 4. ${ }^{a}$ Ed. (São Paulo: Estudio 34, 2017) aponta no protagonista para os traços miseráveis que são radicalmente humanos. Retrata o existente que descobre por si um sentido para a própria vida - um humanismo, mas isso só acentua sua condição miserável - o seu ridículo - conquanto a possibilidade de sua sobrevivência só se deu num face-a-face simultaneamente aleatório e providencial; possibilidade que só pode persistir como memória corpórea - um testemunho de si mesmo ressignificado, mas que não tem a menor necessidade de qualquer discurso reflexivo sobre ipseidade, mundo e alteridade. Isso só fica patente na última frase do conto, que revela tanto o ridículo no discurso do protagonista, como a inflexão de sua sobrevivência: «E, quanto àquela menininha, eu a encontrei... E vou prosseguir! E vou prosseguir!». 
Portanto, a dimensão trágica dos personagens apresenta os limites negativos da condição humana. Essa preocupação está tão presente em narrativas do autor que elas assumem configurações anárquicas. Enredos parecem não se direcionar para algum desfecho e muitos personagens parecem gratuitos no seu tecer da intriga romanesca. O leitor com frequência se sente perdido com o falatório dos personagens. Dostoiévski está recusando a conceituação como chave para um amadurecimento histórico da humanidade. O contraste é patente com os discursos hoje ordinários, pois neles o mal, como uma presença, resta associada quase sempre ao preconceito, de modo que a conceituação seja uma ação antitrágica. Ou seja, via de afirmação tanto escolástica como pós-metafísica, o mal é uma ausência, e não uma presença.

Aqui então é conveniente voltar ao falatório inconclusivo de seus personagens. Essa característica é tão marcante que leva seu estudo à polifonia. É sabido que a dialética, desde os tempos da academia platônica, é uma reflexividade do diálogo. Mas Dostoiévski está empenhado em recusar a dialética como metanorma descritiva da sua narrativa.

Dostoiévski está particularmente preocupado com o romantismo alemão, que começava a encontrar repercussão na Rússia de seu tempo. Uma característica do romantismo é pensar "dispositivos» de instauração da capacidade de superação das contradições humanas metanormas da subjetividade. Essa pretensão encontra na dialética hegeliana sua expressão epítome. Dostoiévski vê nisso uma inconsistência ontológica e vislumbra a dimensão trágica num abandono da humanidade, quando entregue ao seu próprio espírito.

A autonomia dos modernos numa narrativa humanista (típica do romantismo alemão) faz da história lugar de realização da verdade. Na obra de Dostoiévski, há um confronto direto com este postulado. Pulsa nela a agonia de quem se descobre possuidor de uma coerência que não vai além de um desejo de dominação. O que desmantela qualquer arquitetura para suas interações com outros personagens e com os cenários de suas narrativas. Os personagens expressam uma patologia na subjetividade humana que despedaça a higidez do sujeito moderno. A impossibilidade de reconciliação dele com o mundo se expressa como vacuidade da existência diante de uma natureza indiferente ao ego, uma vez que se mostra ilusória qualquer razão suficiente. O esclarecimento é incapaz da maioridade intelectual pretendida e a manifestação patológica disso é o ressentimento. Ressentidos estamos, quando nos parece que não somos agraciados o suficiente pelo destino do que mereceríamos em nossa própria destinação. De certo modo, a declaração dos Direitos Humanos é patologicamente uma usina de ressentimentos pelo mundo, sempre travestido como engajamento num bom 
combate 25 . De modo que essa patologia é a fisiologia do niilismo que torna sem fundo imanente a dignidade como valor-fonte do ser humano.

Giddens reconhece essa patologia e sugere um desvio da intencionalidade desse abismo existencial: a promoção vigilante de uma rotina prática. Este é um sentido para seu realismo. Mas, vejamos o que toca ao seu predicado (um tanto paradoxal) utópico. Para isso, quiçá seja oportuno recurso a Isaiah Berlin. Porque toda utopia tem a ver necessariamente com liberdade. E é bastante conhecido o ensaio de Berlin intitulado Two Concepts of Liberty. Nele, Berlin se lança ao desafiante propósito de totalizar, pela dialética, a liberdade. Para isso, contrapõe um conceito «negativo» a outro "positivo». O conceito negativo emerge da insistência em se perguntar: "Qual é a área em que o sujeito —uma pessoa ou um grupo de pessoas - é ou deve ser deixado para fazer ou ser o que ele é capaz de fazer ou ser sem interferência de outras pessoas?». O conceito positivo emerge de outra pergunta insistente: «Qual ou quem é a referência de controle e interferência que pode determinar alguém a fazer ou ser isso ao invés daquilo?» ${ }^{26}$. A dialética então se dá entre um conceito formal de liberdade (liberdade de ...) e outro material (liberdade para...). A partir daí, Berlin se lança a uma ponderação situacional em busca de um equilíbrio ótimo possível, embora delicado e sempre instável.

Berlin parece estar pensando em Dostoiévski, quando recusa: «Não digo que o ideal de auto-aperfeiçoamento — tanto para os indivíduos, nações, igrejas ou classes- deve ser condenado em si mesmo, ou que o idioma que foi usado em sua defesa foi em todos os casos resultado de um uso de palavras confuso ou fraudulento, ou de perversidade moral ou intelectual». Fica mais patente essa evidência, quando, no

25 «Os direitos do indivíduo deixam de fazer sentido assim que ele deixa de ser um ente alienado, privado do próprio ser, estranho a si mesmo, como o foi nas sociedades de exploração e de penúria, mas onde se tornou, segundo sua fórmula pós-moderna, autorreferencial e autoperformático. O sistema de direitos humanos torna-se completamente inadequado e ilusório em tal conjuntura - o indivíduo flexível, móvel, de geometria variável já não é um sujeito de direito, é um tático promotor da própria existência; já não se refere a nenhuma instância de direito, mas apenas à qualidade de sua atuação ou performance. É hoje, entretanto, que os direitos humanos adquirem atualidade mundial. É a única ideologia atualmente disponível. Por aí, se vê o grau zero da ideologia, o saldo de toda história. Direitos humanos e ecologia são as duas tetas do consenso (....) Será que a apoteose dos direitos humanos corresponde à ascensão irresistível da asneira, essa obra-prima em perigo mas que promete iluminar o fim do século com todos os refletores do consenso?». Jean Baudrillard, A transparência do mal. 2. ${ }^{a}$ Ed. Trad. Estela dos Santos Abreu (Campinas: Papirus, 1992), 95-96.

26 Pondé, Crítica..., 122, 212. 
mesmo parágrafo, concede: «Se, como acredito, os fins dos homens são muitos, e nem todos eles são, em principio, compatíveis uns com os outros, então a possibilidade de conflito —e tragédia- pode nunca ser eliminada da vida humana, nem pessoal e nem social.» ${ }^{27}$ Este posicionamento «lá e cá» de Berlin é convergente com a noção de risco na obra de Giddens.

Porém, devo insistir no Dostoiévski por aquilo que parece desmentir a liberdade dialética no discurso de Berlin, a sua desmoralização. Luiz Felipe Pondé chama esse desmentido de liberdade incriada, porque é intratável pela norma ${ }^{28}$. Intratável, porque radicalmente silenciosa. Mas, se manifesta nos movimentos viscerais do ser humano em suas pulsões de autodestruição. Freud identificará (em seu ensaio sobre o russo) tal liberdade à culpa ${ }^{29}$ e ela é magistralmente evidenciada nas peripécias do protagonista de Crime e Castigo. De modo que não há superação possível das contingências do mundo pela argumentação, e sim pelo atravessamento delas num face-a-face necessariamente silencioso: uma metanoia que não é um equilíbrio frágil que se diga sustentabilidade, mas a condensação de toda escatologia num acontecimento dramático radicalmente pessoal - uma afetividade não intelectiva. Daí que o Princípe de Dostoiévski seja antimaquiavélico sem qualquer resolução dialética nisso. Ele é um governante que responde pelo título de outro romance: O Idiota. Quanto mais alheio à racionalidade estratégica relativista (niilismo racional), mais bondoso. Mas, também mais impotente. Talvez por isso a moral e o Direito estejam hoje fugindo da culpa com a (quiçá obsessiva) objetivação das responsabilidades.

\section{O Castelo de cristal e o homem-rato no seu subsolo}

Notas do Subterrâneo partem de um monólogo do protagonista, que assim se apresenta:

Fui funcionário público (....) recebia propinas ${ }^{30}$, era essa a maneira que encontrava de me compensar (piada fraca, mas não a suprimirei.

27 Pondé, Crítica..., 168-169.

28 Pondé, Crítica..., 32.

29 Sigmund Freud, «Dostoiévski e o parricídio» em Edição standard brasileira das obras psicológicas completas de Sigmund Freud. Tradução de J. Salomão. v. 21 (Rio de Janeiro: Imago, 1969), 203-223.

30 Parece haver um erro de tradução na edição aqui utilizada, que traduz que o narrador recebia propinas, enquanto o russo original diz que não («Ведь я взяток не брал»), o que se repete na tradução de Oleg Almeida. (Fiodor Dostoievski, Diário do 
Escrevi-a pensando que ficaria muito engraçado, mas - agora que percebi que apenas queria mostrar-me sob um aspecto desprezíveldecididamente não a suprimirei!).

Menti há pouco ao dizer que fui um mau funcionário. Foi por despeito que menti. (....)

Não consegui chegar a ser coisa alguma, nem sequer mau; nem mau nem bom, nem canalha nem homem de bem, nem herói nem inseto. E agora termino minha vida no meu canto, escarnecendo de mim mesmo com o inútil e despeitado consolo de que um homem inteligente não pode vir a ser nada de sério e de que só o idiota o consegue.

(...) Aliás, de que assunto um homem decente pode falar com o maior prazer? Resposta: de si mesmo. Pois bem, então vou falar de mim mesmo ${ }^{31}$.

Não é exagero afirmar mesmo que este monólogo é um manifesto de Dostoiévski para apresentação de narrativas que criou depois dele ${ }^{32}$. Já nas primeiras linhas da obra se apresentam as principais características da escrita do autor. Há uma habilidade patente em criar uma polifonia, em que pese ser um monólogo: o protagonista afirma algo só para no instante seguinte se desdizer. As contradições são tantas que se tornam insolúveis. Todos os discursos são iniciados apenas para serem desfeitos.

Um funcionário público anônimo. Dele, logo sabemos corrompido. Em que sentido? Ressentido. O mal está presente em suas vísceras como uma patologia neurótica em sua psiquê. Na falta de um nome para ele, chamá-lo-ei homem-rato:

Subsolo. [São Paulo: Martin Claret, 2012], 19) Curiosamente, este erro não faz diferença para a caracterização do personagem, visto que pouco importava ao servidor público a moralidade de se receberem propinas, vistas como parte da remuneração em uma nem tão antiga cultura de maus salários compensados por "gorjetas».

31 Fiodor Dostoiévski, Notas do Subterrâneo. Tradução de Moacir Werneck. (Rio de Janeiro: Bertrand Brasil, 2003), 9-12.

32 «A presença do homem do subsolo parece soberana no texto, embora nem Vieltcháninov nem Trussótzki sejam meras projeções do famoso paradoxalista. (....) Os tipos são diferentes, as motivações do cotidiano são outras, mas tudo, evidentemente, é relacionado pelo autor com os acontecimentos da década de 1860 na Rússia, quando ocorriam as reformas promovidas por Alexandre // e havia um sentimento de desafogo, a ponto de já se falar muito de glasnost, isto é, o estado da sociedade em que tudo aparece à luz do dia. O homem do subsolo seria aquele que ficava à margem deste movimento, embora, é evidente, o tipo seja muito universal». Boris Schnaiderman, "Posfacio» em Fiódor Dostoiévski, O eterno marido. Trad. Boris Schnaiderman. 3. ${ }^{a}$ Ed. (São Paulo: Estudio 34, 2010), 208. 
Verificar-se-á que o homem feito em retorta fica às vezes tão anulado diante de sua antítese que com toda a sua consciência apurada chega ao ponto de se considerar um rato, e não um homem. (....) E lá, no seu imundo e fétido subterrâneo, o nosso rato, insultado, derrotado e ridicularizado, logo mergulha em sua raiva fria, envenenada e sobretudo infindável. Durante quarenta anos lembrar-se-á dos pormenores mais ignominiosos do insulto recebido, acrescentando a cada vez outros mais ignominiososo ainda, mortificando-se e atormentando-se malignamente com sua própria imaginação 33 .

A liberdade incriada, aquela que desmoraliza qualquer princípio moral, nos é mostrada como uma confissão desse anônimo:

Dizei-me: como é possível que no mesmo, sim, no mesmo instante em que eu era mais capaz de sentir todos os matizes do «belo e do sublime», (....) me acontecesse, como de propósito, não somente pensar, mas também cometer ações abjetas, que... Bem, em suma, ações que talvez todos cometam, mas que, como de propósito, me ocorriam toda vez que eu mais tinha consciência de que deviam ser evitadas? (....) o prazer do desespero, pois é o desespero que encerra os mais intensos prazeres, particularmente quando se tem uma aguda consciência da própria situação ${ }^{34}$.

A consciência aguda a que se refere o protagonista é do dinamismo mortal que anima o desejo.

A liberdade incriada se manifesta no ressentimento, por isso mesmo normalmente se manifesta num subterrâneo pessoal e social e costuma estar fora da construção, quando se proseia sobre ética como uma lógica da moralidade:

O que torna esse interesse [ressentido] particularmente notável é o fato de que destrói todas as nossas classificações e derruba permanentemente todos os sistemas edificados pelos adoradores do gênero humano para a felicidade do gênero humano. Numa palavra, opõe-se a tudo. Mas antes de vos dizer de que interesse se trata, quero comprometer-me pessoalmente: e por isso me atrevo a declarar que todos esses belos sistemas, todas essas teorias que pretendem explicar à humanidade quais são os seus interesses verdadeiros e normais - a fim de que ela se torno logo virtuosa e nobre em seu esforço para atingir os ditos interesses—, são, a meu juízo, mera ló-

33 Dostoiévski, Notas..., 18-19.

34 Dostoiévski, Notas..., 14-15. 
gica! Sim, lógica. (....) Mas o homem tem uma tal paixão pelos sistemas e pelas conclusões abstratas que não hesita em deformar deliberadamente a verdade, em deixar de ver o que está vendo e de ouvir o que está ouvindo, só para justificar a lógica ${ }^{35} .35$

Introduzo neste ponto o palácio de cristal: a arquitetônica de toda moral com que se pretenda afirmar um bem principiológico vinculado a um fim programático sem uma sombra escatológica sequer - um programa de superação, e não de travessia pela escassez, violência e engano:

No palácio de cristal, ele [o sofrimento] seria inimaginável: sofrimento significa dúvida, significa negação, e que seria do palácio de cristal se coubesse nele alguma dúvida? (...) O sofrimento é a única fonte de consciência ${ }^{36}$.

Ele se contrapõe ao otimismo humanista originário da Renascença, isto é, a autoimagem humanista de dignidade essencial no ser humano a proclamar razões suficientes e, com ela, a autonomia de si como ser sócio-político. Com a presença dos homens-ratos no subsolo dos palácios de cristal, desnuda o recalcamento do incerto pela planificação da performance, quando pressupõe uma racionalização total da história, da linguagem ou da natureza. Ou seja, em toda formulação conceitual que pretenda possível um expurgo progressivo do mal pela conscientização de que sua presença nada mais é do que ignorância, preconceito ou despropósito. Ou seja, uma ausência ${ }^{37}$. Todo palácio de cristal tem um elemento lógico comum: a interdição, em seu interior, do ente que escapa às funções dadas pela racionalidade. A sociedade de risco é povoada com palácios de cristal, quando recusa a tragédia, mas seus restos vão habitar, como ratos, o seu subsolo: os ressentimentos.

A narrativa polifônica desconfia da dialética como busca de superação do trágico. Quando, num palácio de cristal, se crê estarmos superando uma tragédia com um manejo da uma matriz de riscos. Palácio de cristal alude ao recalque do que já aconteceu: a degeneração na democracia grega ao tempo em que houve a interdição da tragédia38.

35 Dostoiévski, Notas..., 32-33.

36 Dostoiévski, Notas..., 44-45.

37 «Já não sabemos enunciar o mal. Só sabemos proferir o discurso dos Direitos Humanos. É a minimilização do Mal, profilaxia da violência, segurança (....) que se recusa a encarar a curva do Mal, a inteligência do mal». Baudrillard. Transparência..., 93-94 .

38 Cf. Richard C. Sewell. "The Theatre of Dionysos: Democracy and Tragedy» em Ancient Athens (Jefferson: McFarland \& Company, 2007). 
O rompimento entre a razão de Estado e a dramaturgia trágica clássica se deu, quando foi concebida uma ordem social com a qual os helenizados seriam capazes de alcançar a felicidade a partir de uma epistemologia. Isto é, a felicidade seria uma conquista de uma existência conciliada consigo mesma dentro do mundo - o bem supremo. Dostoiévski profetiza: Não! à toda tentativa de totalização formal da ética. É o que acontece, quando a tratamos como uma lógica da moral, ou dos juízos, ou das ações práticas ${ }^{39}$. Gente sã e normal é «do bem» e, se muito bem cuidada pelo Estado e pela iniciativa privada, vai viver "de boa». Lógica imperial. Aí, uma cidade resplandecente com seus palácios de cristal manifesta, de novo, a vocação humana em erguer impérios. Imperiosa é a formatação da vida como um saber de moderação que objetiva a organização de eventos da vida política e econômica e, ao mesmo tempo, reduz toda subjetividade à psicologia e, no máximo, à fé passível de traduções em discursos laicos. Império é o ethos que recusa o pathos trágico. Nega a tensão entre o humano e a ordem. Ou melhor, a única tensão admissível é a que for apropriada pela dialética. É a tensão tratada pela cognição histórica das necessidades.

Homens-ratos no subsolo, no entanto, são positivações da insegurança capaz de abalar a serenidade de um mundo mergulhado na objetividade da presença (mesmo que virtual) do perigo no risco. A razão comunicativa de Habermas, a pragmática transcendental de Apel e a democracia cooperativa de Dewey são analíticas que pedem, e esperam, uma saída. O realismo de Dostoiévski, contudo, está de certo modo mais alinhado com a frieza de Posner ${ }^{40}$ ou o banho-maria de Rorty ${ }^{41}$, que se conformam em não haver saída alguma a se esperar.

39 Sobre a perspectiva da ética como lógica racional prática da moral, ver as clássicas postulações de Immanuel Kant em Crítica da Razão Pura. Tradução de Manuela P. dos Santos e Alexandre F. Morujão. (Lisboa: Fundação Calouste Gulbenkian, 1989), assim como os comentários sobre o tema feitos por Christine Korsgaard em The Normativiy of Instrumental Reason, Ed. por G. Cullity e B. Gaut. (Oxford: Oxford University Press, 1997) 215-254.

40 Richard Posner em Law, Pragmatism and Democracy (Cambridge/Londres: Harvard University Press, 2003) argumenta por um pragmatismo duro, realista, pelo qual define a democracia como gestão da vontade de potência (impulso irracional nietzschiano), no sentido de que a multiplicidade de interesses é domesticada pela alternância de poderes. O diálogo democrático, então, não busca fundamento teleológicos, sendo contudo um fim em si mesmo.

41 Se assumirmos que, pelo próprio fator humano na produção do discurso, a linguagem não é necessariamente capaz de descrever nada adequadamente, a única forma de se lidar com a ambiguidade seria através do consenso. Se a linguagem não se referir à realidade, pois, mais vale a pena que o objeto do diálogo seja a própria lin- 
Resta fazer o possível para dar um jeito de sustentar a civilização, enquanto der pé: o niilismo racional é assumido sem atenuante, agressivo. Maquiavélico!42 $\mathrm{O}$ equilíbrio não é um valor transcendente. Porque sempre provisório, torna o mundo radicalmente transitório.

\section{Agora sim, posso falar nas cooperativas}

O realismo trágico de Dostoiévski chama atenção para uma vivência desagradável: o ressentimento. O desagradável aí já é uma expressão ética em face à narrativa trágica pensada pelos gregos antigos. Dostoiévski nos convida a repensar os fins de uma objetificação das responsabilidades jurídicas hábeis às antecipações dos danos na culminância dos procedimentos corretos para as performances institucionais a partir dos riscos matriciais. Giddens nos lembra que tal correção tem o condão de preservar a segurança ontológica. Que, na visão de mundo desse russo, significa manter, na prática, os ratos no subterrâneo das cooperativas, longe da luz dos dias. O perigo é o crepúsculo, que precisa ser adiado incessantemente. $E$, para isso, as cooperativas contam com os riscos traçados pelas rotinas técnicas. Mas, isso também significa que eles, os ratos, nossos ressentimentos, estão lá roendo todo fundamento e entortando todo fim. Confundindo toda ética com a estética no horizonte teleológico de bem-estar dos cooperados.

Eis a ética mínima43: liberdade pessoal sustentável social e ambientalmente. Uma lógica prática do eu, cooperado para a constituição do

guagem. Resolverá nossos problemas? Provavelmente não, mas assim respiramos um pouco. Sobre a problemática, cf. Richard Rorty, Contingência, ironia e solidariedade (Lisboa: Presença, 1992).

42 «O fim prova as ações, dizem. Não veja boa sorte, o que segue extravagante, que o fim da ação a prova dela seja.» (Miguel do Couto Guerreiro em Cartas de Ovidio chamadas Heroides, expurgadas de toda a obscenidade, e traduzidas em rima vulgar (Lisboa: Francisco Luiz Ameno, 1789), 46-47.

43 «De facto la convivencia de distintas morales que pretenden universalidad ha sido, y es, posible sobre la base de una ética cívica, que se compone de unos mínimos compartidos entre las distintas ofertas de «máximos», entre las distintas propuestas de felicidad. A la felicidad se invita, mientras que los mínimos de justicia de la ética cívica se exigen. Nadie puede exigir a otro que viva según un modelo de felicidad: puede invitarle a seguirlo. Pero una sociedad sí puede exigir a los ciudadanos que vivan según unas orientaciones de justicia. Por eso es posible de facto el pluralismo moral: porque ya hay unos mínimos de justicia (libertad, igualdad, diálogo, respeto) compartidos por las morales de máximos. Y esta moral cívica orienta la legalidad, que no sólo se exige, sino que se impone, si es necesario, mediante sanción.» Adela Cortina, Ética mínima: introducción a la filosofía práctica. 6. ${ }^{a}$ Ed. (Madri: Tecnos, 2000), 83. 
plural: nós, a assembleia. Se essa moral é plástica e performática, não ousa dizer seu nome, porque não se quer confundida com as máximas morais. Nascida da política moderna, não cansa de proclamar com otimismo a dignidade essencial da pessoa. Por seu imaginário minimalista, é uma ética universal, finalmente amadurecida. E desliza para sua degeneração: uma lógica da moralidade.

Toda lógica é neutra. Uma ética neutra para as diversidades históricas e coexistência multicultural. Uma ética mínima, neutra e prática.... e universal, ainda que comunitária. Sua lógica universal é dialética entre a dignidade igual para todos no princípio e a sustentabilidade fraterna no fim. Este, sempre adiado por um projeto de autonomia de si que nunca acaba, porque o eu, cooperado se reinventa a cada instante a propor novas alianças entre nós, assembleia. Aparentemente, não precisamos mais carregar culpa alguma. Apenas assumir responsabilidades para nossas competências intelectivas e emocionais a serem tratadas como uma questão de performance e responsividade.

Dostoiévski, no entanto, nos incomoda com sua denúncia profética da presença insuperável do mal: mysterium iniquitatis. Irredutível a uma ausência de conhecimento, pois seu radical originário sempre aponta para a dramaticidade da condição humana. Por ele, resgatamos para a época moderna ${ }^{44}$ a ambiguidade do antiquíssimo cântico de Salomão: fusca sum et decora ${ }^{45}$.

Entre Dostoiévski e a ética mínima, posso situar Baudrillard, que se dedicou ao mal, enquanto Giddens pensava o risco. Baudrillard chama compulsão para amputações cirúrgicas a remodelação da ética por operações de síntese (racionalidade metaética), porque, daí, traços negativos restam retraídos do texto ${ }^{46}$. Para demonstrar o que postula, o francês recorre de modo catafático ao verbo fazer. Este verbo aí indica que se trata de uma operação, não mais de um ato, ou mesmo cadeia qualquer de atos. Isto é, o verbo ativo cede a vez ao auxiliar que é fatitivo. $\mathrm{O}$ ato em si tem menos importância que o fato de ser ele produzido, induzido, solicitado, mediatizado, tecnicizado A comunicação deixa der ser o falar; é fazer-falar. E a informação não é mais conhecimento, mas o fazer-conhecer. Quedam-se sem sentido ações além dos que resultam de alguma interação, se possível com uma tela de controle e retroalimentação incorporada ${ }^{47}$. Nessa compulsão operacional se mostra o paradoxo da ética mínima: não apenas se trata de fazer-

\footnotetext{
44 Ver nota 22.

45 Sou negra e bela. Cântico dos Cânticos de Salomão 1:4.

46 Baudrillard, A transparência...., 52.

47 Baudrillard, A transparência..., 53.
} 
valer, mas o melhor ainda é nada-valer para melhor fazer-valer. Tudo isto está na lógica da performance: nada saber para melhor fazer-saber —nada produzir para melhor fazer-produzir - nada ter que dizer para melhor comunicar. Baudrillard descreveu a consequência, que reconheceu inexorável, para a comunicação e a informação: numa otimização da performance, o conteúdo precisa derivar para o limite da transparência. E, de mãos dadas com a transparência, a insignificância. A partir do texto de Baudrillard, pode-se recuperar, da ética mínima, um traço negativo que já ia vislumbrado na estética, nos idos anos 80 : o abandono do interesse pela forma e a ênfase na performance. Esta é operacional, porque não visa alguma forma plástica, mas sua fórmula de plasticidade, sua equação, algoritmo, sua virtualidade como terreno de operação ${ }^{48}$.

\section{Conclusão: do homo politicus no homo felix}

Não prego a recusa do discurso da $\mathrm{ACl}$ sobre ética para as governanças cooperativas com sua gestão de riscos. O discurso tem o mérito de viabilizar adesão dos stakeholders às políticas da cooperativa que persigam objetivos de médio e longo prazos. Falar em moral não tem o mesmo apelo de uma ética mínima, uma vez que esta se articula com o imaginário da autonomia de si como maioridade do eu, cooperado -um mito moderno ${ }^{49}$.

É uma estratégia eficaz adotar o discurso da ética mínima e responsabilidades objetivas compatíveis com a consumerística que demanda práticas cada vez mais performáticas e responsivas até mesmo das políticas públicas. Mas, não por ser ético. E sim, porque é moral: viabiliza a adaptação das cooperativas ao seu ambiente social, econômico e ju-

48 Baudrillard, A transparência..., 55-56.

49 «Mesmo quando a lenda não se denuncia imediatamente pela presença de elementos maravilhosos, pela repetição de motivos conhecidos, pelo desleixo na localização espacial ou temporal, ou por outras coisas semelhantes, pode ser reconhecida rapidamente, o mais das vezes por sua estrutura. Desenvolve- se de maneira excessivamente linear. Tudo que correr transversalmente, todo atrito, todo o restante, secundário, que se insinua nos acontecimentos e motivos principais, todo o indeciso, quebrado e vacilante, tudo o que confunde o curso claro da ação e a simples direção das personagens, tudo isso é apagado. (....) A lenda ordena o assunto de modo unívoco e decidido, destaca-o da sua restante conexão com o mundo, de modo que este não pode intervir de maneira perturbadora (....) Escrever história é tão difícil que a maioria dos historiadores vê-se obrigada a fazer concessões à técnica do lendário. «Erich Auerbach, Mimesis: a representação da realidade na literatura ocidental. 6. ${ }^{a}$ Ed. Vários tradutores. (São Paulo: Perspectiva, 2018), 16-17. 
rídico dado. Há uma questão de custo de transação a ser considerada adequadamente.

Mas... e quanto aos homens-ratos? Por essa mesma estratégia, a presença deles, mesmo no subterrâneo da cooperativa, é uma ameaça. Então, as cooperativas podem incorporar competências em psicologia para identificá-los no convívio com os aderentes ao discurso analítico-pragmatista para a ética - a barca dos homens operosos. Essa estratégia é eficaz para a iniciativa privada em desencaixe espaço-temporal. No desencaixe, o darwinismo mercadológico premia quem melhor se adapta. Mas, a dimensão da existência trágica se manifesta no reencaixe: homens-ratos podem até ser identificados no dia-a-dia das cooperativas, mas, ao contrário dos colaboradores, cooperados não podem ser facilmente afastados do convívio. Se não têm lugar no palácio de cristal, estarão em seu subsolo. A gestão democrática se assenta sobre um solo que se encharca de mais ressentimento a cada dia.

Chamarei aqui essa patologia social de síndrome Lippy -Hardy, personagens bi-polares do universo Hanna-Barbera. Além do imaginário que os personagens evocam (um não vive sem o outro), a síndrome Lippy-Hardy não é desconhecida para uma gestão bem feita de riscos. Mas, numa sociedade empresária, ela é tratada com um «corte cirúrgico» - detecção e extirpação dos leões imprudentes e das hienas inertes. Mas, nas cooperativas, as hienas são tão cooperadas quanto os leões. São as governanças convocadas para gerirem cooperativas movidas por usinas de ressentimentos.

A síndrome Lippy-Hardy é o conjunto de características do que Lipovetsky chamará de paradoxo da felicidade ${ }^{50}$ : a coexistência de uma atmosfera de entretenimento espetacular e experienciação estética com a ansiedade pandêmica - a dissociação possível e até mesmo provável entre conforto e prazer. A síndrome é o aprofundamento de riscos permanentes da gestão democrática em qualquer cooperativa, desde cedo identificados por Tocqueville (2005): frustração dos desejos insaciáveis, agitação psicológica e preocupações penosas. O ressentimento assume particular relevo sintomático, porque a frustração dos desejos numa febre performática-produtiva sempre emergirá com uma percepção do rebaixamento, um descrédito infamante de si para si.

Não que agora os ressentimentos sejam mais intensos, mas eles se tornam mais frequentes na febre performática-produtiva, pois

50 Gilles Lipovetsky e SERROY, Jean Serroy, A estetização do mundo: Viver na era do capitalismo artista. Tradução de Eduardo Brandão. (São Paulo: Companhia das Letras, 2015), 4. 
ela se liga diretamente à idealização da felicidade como algo que se busca e está ao alcance de todos numa maioridade filosófica: a autonomia de si.

Lipovetsky indica quatro vetores que potencializam a frequência das decepções motoras dos ressentimentos nos dias atuais: (1) o fracasso das utopias, sem que, no entanto, se realizem distopias; (2) o sistema programático dos Direitos Humanos como, ele próprio, uma utopia; (3) a espetacularização da política; e (4) a impotência do poder público como instrumento supremo de unidade e coesão sociais, vetor suficiente de igualdade, instância por excelência produtiva do bem estar e, por isso, garantidor dos laços sociais ${ }^{51}$.

Porém, como Lipovetsky assevera, não se trata de «formular o esboço de um futuro que mais parece uma predestinação fata/» ${ }^{52}$ Tratase mais de compreender os aspectos paradoxais da reflexidade inquieta ${ }^{53}$ e, com esta compreensão, evitarmos a tentação moderna de nos dizermos capazes da construção de cooperativas sem sombras para o desenvolvimento humano ${ }^{54}$ : a transparência como um princípio ético ${ }^{55}$. Em termos de ambiência política impregnada de funcionalismo ${ }^{56}$, então uma pergunta se mostra essencial: o que se consegue afinal com cristalina transparência ${ }^{57}$

51 Lipovetsky e Serroy. A estetização..., 42-44.

52 Lipovetsky e Serroy. A estetização..., 57.

53 Lipovetsky e Serroy. A estetização..., 61.

54 Lipovetsky e Serroy. A estetização..., 68.

55 Valor aqui tem um sentido ontológico próprio da fenomenologia transcendental: um ente material e ideal, numa relação de identidade e diferença com o fato, que sempre é ente material e formal e o lógico - ente formal e ideal.

56 «A liberdade não parece oferecer riscos enquanto as coisas obedientemente seguem o caminho que desejamos. Afinal, a liberdade é a capacidade de fazer com que as coisas sejam realizadas do modo como queremos, sem que ninguém seja capaz de resistir ao resultado, e muito menos desfazê-lo.» Zygmunt Bauman, Comunidade: a busca por segurança no mundo atual. Tradução de Plínio Dentzien (Rio de Janeiro: Zahar, 2003), 26.

57 Bastante conhecidos os versos de Mário Quintana no poema «As indagações» em Poesia Completa, editado por Tânia Franco Carvalhal (Rio de Janeiro: Nova Aguilar, 2006), 178: "A resposta certa, não importa nada: o essencial é que as perguntas estejam certas.» Para compreender os versos, é chave o sentido propriamente fenomenológico da expressão essência. Essência é a pura possibilidade de algo ser real, isto é, vigente para todos. A essência é o transcendente, isto é, o que, de um ente, a ele sempre se remete toda vivência. Embora todo ente sempre apareça através de uma vivência (seu fenômeno), sua essência vai se mostrando naquilo que, da vivência, seja mais do que sua impressão e expressão, sua demonstração analítica (por exemplo, causas e consequências), sua observação empírica, uma convenção entre potências volitivas, um dogma, enfim, mais do que linguagem. A essência de qualquer ente é sua possibilidade necessária para intuí-lo no âmbito das hipóteses. Sem sua essência, o ente se destrói 


\section{Referências Bibliográficas}

ARNÁEZ, Vega M. a . 2018. "La alternativa cooperativa en la prestación de servicios públicos sostenibles». Boletín de la Asociación Internacional de Derecho Cooperativo 52: 123-135. doi: http://dx.doi.org/10.18543/baidc-522018pp123-135

AUERBACH, Erich. 2018. Mimesis: a representação da realidade na literatura ocidental. 6. ${ }^{a}$ edição. Vários tradutores. São Paulo: Perspectiva.

BAUDRILLARD, Jean. 1992. A transparência do mal. 2. ${ }^{a}$ ed. Trad. de Estela dos Santos Abreu. Campinas: Papirus.

BAUMAN, Zygmunt. 2003. Comunidade: a busca por segurança no mundo atual. Tradução de Plínio Dentzien. Rio de Janeiro: Zahar.

BELATEGI, Onintza; GAGO, Mónica y EGAÑA, Txema. 2019. «La comunicación interna en las cooperativas: la percepción de las personas trabajadoras sobre la escucha y la información». REVESCO. Revista de Estudios Cooperativos, 130: 9-32. doi: http://dx.doi.org/10.5209/REVE.62812

BELL, Daniel. 2004. Las contradicciones culturales del capitalismo. Madrid: Alianza Editorial.

BRETOS, Ignacio y ERRASTI, Anjel. 2018. «La transmisión de los valores y prácticas organizacionales cooperativas en las filiales extranjeras: El caso de la cooperativa multinacional Fagor Ederlan». REVESCO. Revista de Estudios Coperativos, 127: 45-69. doi: http://dx.doi.org/10.5209/REVE.58395

BUSTAMANTE, Alina Marcela. 2019. "Gestión humana socialmente responsable en cooperativas de trabajo asociado colombianas», CIRIEC-España, Revista de Economía Pública, Social y Cooperativa, 95: 217-255. DOI: 10.7203/CIRIEC-E.95.10433

COOKE, Maeve. 1994. Language and Reason: A Study in Habermas's Pragmatics. Cambridge: MIT Press.

CORTINA, Adela. 2000. Ética mínima: introducción a la filosofía práctica. 6. ${ }^{a}$ Edição. Madri: Tecnos.

DEWEY, John. 2008. Democracia cooperativa: Escritos políticos de John Dewey. Organização por Augusto de Franco e Thamy Pogrebinschi. Porto Alegre: EDIPUCRS.

DOSTOIÉVSKI, Fiódor. 2003. Notas do Subterrâneo. Tradução de Moacir Werneck. Rio de Janeiro: Bertrand Brasil.

DOSTOIÉVSKI, Fiódor. 2012. Diário do Subsolo. Tradução de Oleg Almeida. São Paulo: Martin Claret.

DOSTOIÉVSKI, Fiódor. 2017. Duas Narrativas Fantásticas. Tradução de Vadim Nikitin. 4. ${ }^{a}$ Edição. São Paulo: Estudio 34.

FOUCAULT, Michel. 2007. "What is Critique?» In The Politics of Truth. Edição de Sylvère Lotringer. Nova lorque: Semiotext(e).

como possibilidade de presença para todos. Essência de um ente é o que dele permanece em toda variação imaginária (intencionalidade) voltada ao próprio ente. 
FREUD, Sigmund. 1969. «Dostoiévski e o parricídio». In Edição standard brasileira das obras psicológicas completas de Sigmund Freud. Tradução de J. Salomão. Rio de Janeiro: Imago, v. 21, pp. 203-223.

GIDDENS, Anthony. 1991. As consequências da modernidade. São Paulo: Editora UNESP.

GUERREIRO, Miguel do Couto. 1789. Cartas de Ovidio chamadas Heroides, expurgadas de toda a obscenidade, e traduzidas em rima vulgar. Lisboa: Francisco Luiz Ameno. https://archive.org/details/cartasdeovidioc00ovidgoog. Acesso em: 17 set. 2018.

KANT, Immanuel. 1989. Crítica da Razão Pura. Tradução de Manuela P. dos Santos e Alexandre F. Morujão. Lisboa: Fundação Calouste Gulbenkian.

KORSGAARD, Christine. 1997. "The Normativiy of Instrumental Reason». In CULLITY, G.; GAUT, B. (eds.). Oxford: Oxford University Press, pp. 215254.

KRUEGER, Guilherme. 2016. "Cooperativas e madalenas». Boletín de la Asociación Internacional de Derecho Cooperativo, 50: 241-283. doi: http:// dx.doi.org/10.18543/baidc-50-2016pp241-283

KRUEGER, Guilherme. 2018. "A cooperativa sem degredados: uma esquizoanálise da sua promessa de felicidade». Boletín de la Asociación Internacional de Derecho Cooperativo, 53: 225-250. doi: http://dx. doi. org/10.18543/baidc-53-2018pp225-250

LIPOVETSKY, Gilles; SERROY, Jean. 2015. A estetização do mundo: Viver na era do capitalismo artista. Tradução de Eduardo Brandão. São Paulo: Companhia das Letras.

MAGUREGUI, M. Lorea; Corral, Javier y Elechiguerra, Crisanta. 2019. «La identificación de los grupos de interés de las entidades sin fines de lucro en la emisión de información transparente». REVESCO. Revista de Estudios Cooperativos, 131: 65-85. doi: https://doi.org/10.5209/REVE.62814

NIETZSCHE, Friedrich Wilhelm. 2009. A Genealogia da Moral (3. ${ }^{a}$ ed.). Tradução de Antônio Carlos Braga. São Paulo: Escala.

PONDÉ, Luiz Felipe. 2013. Crítica e Profecia: a filosofia da religião em Dostoiévski. São Paulo: LeYa.

POSNER, Richard. 2003. Law, Pragmatism and Democracy. Cambridge/Londres: Harvard University Press.

QUINTANA, Mário. 2006. Poesia Completa. Organização de Tânia Franco Carvalhal. Rio de Janeiro: Nova Aguilar.

RAINHA, A. 2006. Direção de Stephen Frears. Londres: Granada Productions, 1 DVD (103 min.), son. color.

RORTY, Richard. 1992. Contingência, ironia e solidariedade. Lisboa: Presença.

RYDELL, Anders. 2018. Ladrões de livros. Trad. Rogério Calindo. São Paulo : Planeta do Brasil.

SCHNAIDERMAN, Boris. 2010. "Pósfacio». In Fiódor Dostoiévski. O eterno ma-

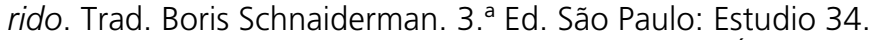

SCRUTON, Roger. 2017. Arte e Imaginação. São Paulo: É Realizações.

SEWELL, Richard C. 2007. In the Theatre of Dionysos: Democracy and Tragedy in Ancient Athens. Jefferson: McFarland \& Company. 
WELLMER, Albrecht. 2004. «Der Streit um die Wahrheit. Pragmatismus ohne regulative Ideen». In BÖHLER, D.; KETTNER, M.; SKIRBEKK, G. (eds.). Reflexion und Verantwortung. Auseinandersetzungen mit Karl-Otto Apel. Frankfurt.: Suhrkamp: pp. 143-170.

VOZ DO MORRO, A. 1965. Coração vulgar. São Paulo: Musidisc. https://www. youtube.com/watch?v=9adaDnzLHm4. Acesso em 15 jan. 2019

ZIOLKOWSKI, Eric. 2001. "Reading and incarnation in Dostoevsky». In PATTINSON, George; THOMPSON, Diane O. (eds.). Dostoevsky and the Christian Tradition. Cambridge: Cambridge University Press, pp. 156-170. 


\section{Derechos de autor}

El Boletín de la Asociación Internacional de Derecho Cooperativo es una revista de acceso abierto lo que significa que es de libre acceso en su integridad inmediatamente después de la publicación de cada número. Se permite su lectura, la búsqueda, descarga, distribución y reutilización legal en cualquier tipo de soporte sólo para fines no comerciales y según lo previsto por la ley; sin la previa autorización de la Editorial (Universidad de Deusto) o el autor, siempre que la obra original sea debidamente citada (número, año, páginas y DOI si procede) y cualquier cambio en el original esté claramente indicado.

\section{Copyright}

The International Association of Cooperative Law Journal is an Open Access journal which means that it is free for full and immediate access, reading, search, download, distribution, and lawful reuse in any medium only for non-commercial purposes, without prior permission from the Publisher or the author; provided the original work is properly cited and any changes to the original are clearly indicated. 